\title{
The interaction of 6-propionyl-2-( $N \mathrm{~N}$-dimethyl)aminonaphthalene (PRODAN)-labelled actin with actin-binding proteins and drugs
}

\author{
Kasper ZECHEL \\ Max-Planck-Institut for Biophysical Chemistry, Department of Biochemistry, P.0. Box 2841, D-3400 Göttingen, Federal Republic of Germany
}

\begin{abstract}
The influence of various actin-binding proteins and drugs on the fluorescence emission of rabbit muscle actin labelled with the fluorescent probe acrylodan (6-acryloyl-2-dimethylaminonaphthalene) at Cys-374, the penultimate amino acid residue of the actin amino acid sequence, was studied. Addition of myosin, tropomyosin or phalloidin, agents known to bind only to filamentous F-actin, did not change the emission energy or the integrated intensity of the fluorescence spectrum. The presence of heavy meromyosin or of the glycolytic enzyme aldolase led to a small (approx. $2 \%$ ) increase in the integrated intensity, and in the energy of the emitted fluorescence. The interaction of 6propionyl-2-( $N N$-dimethyl)aminonaphthalene (PRODAN)-Factin with pancreatic DNAase $I$ and with a filament-severing $19 \mathrm{kDa}$ protein from pig brain resulted in the gradual reduction
\end{abstract}

of the integrated intensity of the emission and a red shift of the emission energy, suggestive of a disintegration of the actin filament structure. Profilin caused a $<10 \%$ change in the emission energy. Cytochalasin D reduced the integrated intensity of PRODAN-F-actin and red-shifted the emission energy, while cytochalasin B was without influence. Pancreatic DNAase I did not change thie fluorescence emission of PRODAN-G-actin, suggesting that binding of this enzyme does not alter the environment of the probe. When the $19 \mathrm{kDa}$ protein bound to PRODAN-G-actin, however, the integrated intensity was reduced and the emission energy was lowered. This effect was exploited to estimate the binding constant for the interaction between the $19 \mathrm{kDa}$ protein and PRODAN-G-actin. The $K_{\mathrm{d}}$ was found to be about $0.25 \mu \mathrm{M}$.

\section{INTRODUCTION}

A variety of fluorescent probes attached to actin have proven valuable in studies of the association of actin promoters (Detmers et al., 1981; Cooper et al., 1983; Zimmerle and Frieden, 1986), and in studies of the interaction of actin with actin-binding proteins (Miki et al., 1982; Doi and Frieden, 1984; Lee et al., 1988). The attachment of reporter groups to a protein bears the inherent risk of interfering with the functional properties of the target molecule. The polymerization reaction of actin, i.e. the formation of F-actin filaments from globular G-actin, however, appears to tolerate a number of fluorophores, for instance 7chloro-4-nitrobenzeno-2-oxa-1,3-diazole (NBD) (Detmers et al., 1981), 5-\{2-[(acetyl)amino]ethyl\}aminonaphthalene-1-sulphonic acid (1,5-AEDANS) (Tawada et al., 1978; Tao and Cho, 1979), dansylaziridine (Lin, 1978; Porter and Weber, 1979) and pyrene (Kouyama and Mihashi, 1981), especially if these probes are linked to the polypeptide at Cys-374, the penultimate residue of the amino acid sequence of actin. In previous work (Marriott et al., 1988) we have introduced PRODAN [6-propionyl-2-( $N N$ dimethyl)aminonaphthalene] as a new fluorescent label for actin and have demonstrated the suitability of the PRODAN-actin conjugate for the investigation of actin-actin interactions. Upon polymerization of $\mathrm{G}$-actin to $\mathrm{F}$-actin, the absorption of the actin-PRODAN conjugate is red-shifted, and the fluorescence emission is blue-shifted by 770 wavenumbers. This shift is accompanied by a decrease in the fluorescence bandwidth of 470 wavenumbers. In addition to the shift, the intensity of the PRODAN-actin fluorescence is increased by approx. $40 \%$. A blue shift of the fluorescence emission was also reported for dansylaziridine-actin upon the G-actin to F-actin transition (Porter and Weber, 1979). However, $70 \%$ of the label was attached to residues other than Cys-374, so that different molecules attached to multiple sites along the actin polypeptide might have contributed to the shift. Other commonly used fluorescent dyes do not shift the emission energy. They usually exhibit only a change in the fluorescence intensity. For instance, the increase in the intensity is of comparable magnitude in the case of NBD and 1,5-AEDANS, and it is an order of magnitude larger than that of PRODAN-actin in the case of pyrene. Fluorescent probes such as PRODAN that exhibit both an increase in the fluorescence intensity and a spectral shift may be advantageous for protein systems where multiple transitions occur, because both parameters can be exploited for the analysis of the equilibria. The change in the fluorescence characteristics of the PRODAN-actin conjugate upon polymerization allows easy quantification of the monomeric-to-polymeric actin ratio. It presumably reflects the change in the environment of the dye ligand. In F-actin the ligand becomes more buried inside the protein structure than in G-actin and hence less accessible to the aqueous environment, as shown by quenching studies with iodide ions (Marriott et al., 1988). Given the ease of monitoring the signal, it appeared interesting to use PRODAN-actin to probe for alterations to the environment that may occur when actin combines with actin-binding proteins and drugs. In this paper I describe the effects that a number of actin-binding proteins and drugs have on the fluorescence emission of the PRODAN-actin conjugate.

\section{EXPERIMENTAL}

\section{Proteins}

Muscle actin was prepared from rabbit leg and back muscle as described by Spudich and Watt (1971), including a gel-filtration step (MacLean-Fletcher et al., 1980). It was labelled in the filamentous form (F-actin) with acrylodan (6-acryloyl-2-

Abbreviations used: G-actin, globular actin; F-actin, filamentous actin; HMM, heavy meromyosin; PRODAN, 6-propionyl-2-(NN-dimethyl)aminonaphthalene; 1,5-AEDANS, 5-\{2-[(acetyl)amino]ethyl\}aminonaphthalene-1-sulphonic acid; NEM, N-ethylmaleimide; NBD, 7-chloro-4-nitrobenzo-2-oxa1,3-diazole. 
dimethylaminonaphthalene) as detailed by Marriott et al. (1988) to a dye/protein ratio of $0.8-0.9$. Myosin has been prepared following a procedure outlined by Pollard (1982). Heavy meromyosin (HMM) was obtained from myosin by mild treatment with trypsin (Lowey and Cohen, 1962). Aldolase (EC 4.1.2.13) and DNAase I (EC 3.1.21.1) (grade CN-S) were products from Sigma (St. Louis, MO, U.S.A.). Profilin was prepared from pig spleen (Carlsson et al., 1977) and tropomyosin was from rabbit muscle (Cummings and Perry, 1973).

The $19 \mathrm{kDa}$ protein has been purified from pig brain. A procedure designed for the partial enrichment of $19 \mathrm{kDa}$ protein from small amounts of HeLa cells (Zechel, 1983) has been extended as follows. All operations were done in a cold room at 4-6 ${ }^{\circ} \mathrm{C}$. Usually about $30 \mathrm{~g}$ of fresh or frozen brain tissue was homogenized in G-buffer ( $2 \mathrm{mM}$ Tris/ $\mathrm{HCl}(\mathrm{pH} 7.9) / 0.2 \mathrm{mM}$ ATP $/ 0.2 \mathrm{mM} \mathrm{CaCl} / 0.2 \mathrm{mM}$ dithiothreitol/1 $\mathrm{mM} \mathrm{NaN}_{3}$ ) containing $0.1 \mathrm{mM}$ phenylmethanesulphonylfluoride, using a Potter-Elvejhem homogenizer. The homogenate was centrifuged at $4{ }^{\circ} \mathrm{C}$ for $1 \mathrm{~h}$ at $100000 \mathrm{~g}$, and the clear supernatant was immediately applied to a DNAase-I-Sepharose affinity column ( $10 \mathrm{ml}$ bed volume containing about $100 \mathrm{mg}$ of enzyme covalently coupled to the matrix) equilibrated with G-buffer. The column was washed with G-buffer until the absorption at $280 \mathrm{~nm}$ had returned to almost zero. The $19 \mathrm{kDa}$ protein was subsequently eluted with $0.5 \mathrm{M} \mathrm{NaCl}$ in G-buffer. The salt was removed by overnight dialysis against $20 \mathrm{mM}$ Tris $/ \mathrm{HCl}(\mathrm{pH} 7.9) / 10 \%$ (w/v) glycerol/0.1 mM dithiothreitol. The salt-free solution was then passed through a DEAE-Trisacryl column (IBF-Biotechnics, Villeneuve-la-Garenne, France; $10 \mathrm{ml}$ bed size) equilibrated with the dialysis buffer. The flow-through, containing the $19 \mathrm{kDa}$ protein, was collected and dialysed exhaustively against $10 \mathrm{mM}$ Hepes/ $\mathrm{NaOH}$ (pH 7.5)/0.1 mM dithiothreitol/10\% (w/v) glycerol. It was then applied to a column of SP-Trisacryl (IBFBiotechnics, $10 \mathrm{ml}$ bed volume) equilibrated with the dialysis buffer. $\mathrm{A} \mathrm{NaCl}$ gradient (0-0.2 $\mathrm{M}$ in equilibration buffer; total volume $60 \mathrm{ml}$ ) was used to elute bound proteins. The $19 \mathrm{kDa}$ protein eluted in a symmetrical peak at about $50 \mathrm{mM} \mathrm{NaCl}$. The peak fractions were pooled, mixed with 2 vol. of $5 \mathrm{M} \mathrm{NaCl}$ and applied to a phenyl-Sepharose column (Pharmacia, Uppsala, Sweden; $5 \mathrm{ml}$ bed volume) equilibrated with $10 \mathrm{mM}$ Hepes/NaOH (pH 7.5)/10\% (w/v) glycerol/0.1 mM dithiothreitol/3.33 M NaCl. In a gradient of decreasing salt concentration, the $19 \mathrm{kDa}$ protein was released in a peak centred around $1.8 \mathrm{M} \mathrm{NaCl}$. It was concentrated to about $2-3 \mathrm{mg} / \mathrm{ml}$ using Centricon 10 microconcentrators (Millipore Corp., Bedford, MA, U.S.A.), washed three times with the Hepes buffer without $\mathrm{NaCl}$ to remove most of the salt, and stored on ice. In this form the $19 \mathrm{kDa}$ protein was stable for several weeks without noticeable loss of activity. The yield was usually around $0.6 \mathrm{mg}$ of purified $19 \mathrm{kDa}$ protein which migrated as a single band on a heavily loaded SDS $/ 15 \%$ polyacrylamide gel (results not shown). Similar if not identical proteins from chicken brain named ADF (Bamburg et al., 1980; Giuliano et al., 1988), from bovine brain named BIP (Berl et al., 1983), and from porcine brain named cofilin (Maekawa et al., 1984) have been described. Recent partial amino acid sequencing data obtained from proteolytic fragments of $19 \mathrm{kDa}$ protein that were compared with the amino acid sequence deduced from the sequence of a cDNA clone of cofilin (Matsuzaki et al., 1988) strongly suggest that $19 \mathrm{kDa}$ protein is probably identical to cofilin from porcine brain (K. Zechel, unpublished work).

\section{Drugs}

$N$-Ethylmaleimide (NEM) was purchased from Sigma (St. Louis,
MO, U.S.A.), and phalloidin was from Boehringer (Mannheim, Germany). Two batches of cytochalasin B were used, one from Sigma and the other from Aldrich-Chemie (Steinheim, Germany). They gave identical results. Cytochalasin D was purchased from Calbiochem (San Diego, CA, U.S.A.).

\section{Methods}

Fluorescence emission spectra were recorded at $1 \mathrm{~nm}$ intervals with an SLM 8000 spectrofluorimeter operated in the ratio mode using photon counting as described by Marriott et al. (1988). The excitation wavelength was set at $380 \mathrm{~nm}$. All measurements were taken at $22^{\circ} \mathrm{C}$ and the samples were illuminated only during measurements in order to minimize intensity losses due to photobleaching. The halfwidths of the spectra were calculated after smoothing of the recorded raw curves using Chebyshev's polynomial approximation $(n=20)$ (cf. Hamming, 1973). Instead of the maximum of the emission, the centre of spectral intensity distribution (called centre of spectral mass) was calculated using the equation:

$$
v=\Sigma v_{\mathrm{i}} \cdot I_{\mathrm{i}} / \Sigma I_{\mathrm{i}}
$$

where $v$ is the average energy of the emission spectrum in $\mathrm{cm}^{-1}$ and $I_{\mathrm{i}}$ is the fluorescence intensity at wavenumber $v_{\mathrm{i}}$. The centre of spectral mass is generally considered to be more accurate than the emission maximum in determining spectral shifts of the fluorescence emission (Lakowicz, 1983).

SDS/PAGE used the Tris/glycine buffer system (Laemmli, 1970) with a $120 \mathrm{~mm} \times 80 \mathrm{~mm} \times 0.75 \mathrm{~mm}$ slab gel. The fluorescent bands were photographed under illumination with u.v. light at $366 \mathrm{~nm}$ using a cut-off filter at $400 \mathrm{~nm}$ in front of the camera lens. After documentation of the fluorescence, the protein bands were stained with Coomassie Brilliant Blue R250. High-shear viscosity was measured in an Ostwald-type viscometer as described previously (Zechel, 1981).

\section{RESULTS AND DISCUSSION}

\section{PRODAN is attached to Cys-374 of the actin polypeptide}

In view of the sensitivity of PRODAN fluorescence to the chemical environment, it appeared necessary to know the attachment site of the fluorophore. Previously we suspected from the established thiol reactivity of acrylodan (Prendergast et al., 1983), from the coupling stoichiometry and from the spectroscopic properties of the conjugate that a single PRODAN moiety was attached to actin, presumably via Cys-374 (Marriott et al., 1988). Figure 1 shows evidence that this supposition is correct. When F-actin was labelled with acrylodan at $\mathrm{pH} 7.5$ a typical labelling ratio of $0.8-0.9 \mathrm{~mol}$ of PRODAN/mol of actin monomer was obtained. The most reactive SH-group in native actin is that of Cys-374, which is known to combine preferentially with many SH-reactive reagents including NEM (Lusty and Fasold, 1969; Elzinga and Collins, 1975). Masking of Cys-374 in F-actin with NEM before the addition of acrylodan (Figure 1, lane 2) prevented almost completely the attachment of fluorescent PRODAN to actin. This result indicates convincingly that PRODAN is in fact linked to the same attachment site as NEM, namely Cys-374 of the actin polypeptide chain.

\section{PRODAN-actin and F-actin-binding proteins}

I tested seven proteins and three drugs, known to interact with either F- or G-actin, to detect whether their binding to actin alters the environment of the PRODAN fluorophore. All proteins 


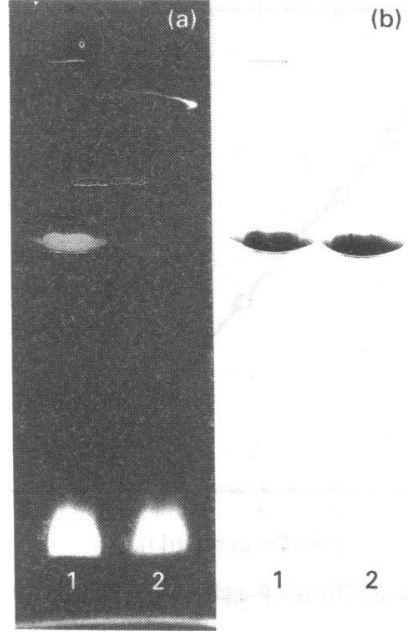

Figure 1 Competition of NEM and acrylodan for Cys-374 of actin

Electrophoresis of $4 \mu \mathrm{g}$ of actin in a $20 \%$ polyacrylamide gel containing $0.1 \%$ SDS. (a) PRODAN fluorescence; (b) the same gel stained with Coomassie Brilliant Blue. Lanes: 1, actin treated with acrylodan only; 2, actin treated first with NEM and subsequently with acrylodan. The fluorescent spots at the lower end of gel represent excess fluorescent dye. They are present because aliquots of the reaction mixtures were loaded on to the gel directly, without removal of the unreacted dye.

Table 1 Changes in PRODAN-F-actin fluorescence caused by the addition of various proteins and drugs

All measurements were done at $22^{\circ} \mathrm{C}$; all proteins and drugs were added in molar excess over actin protomers. Steady-state values are listed relative to $\mathrm{F}$-actin, except those marked with an asterisk (*), which were calculated relative to G-actin. Halfwidth $=$ bandwidth at half of the maximal peak height of the fluorescence spectrum. Results with myosin were obtained in $0.5 \mathrm{M} \mathrm{NaCl}$.

\begin{tabular}{lcll}
\hline & $\begin{array}{l}\text { Difference in } \\
\text { emission energy } \\
(\text { centre of mass) } \\
\left(\mathrm{cm}^{-1}\right)\end{array}$ & $\begin{array}{l}\text { Difference in } \\
\text { integrated } \\
\text { intensity } \\
(\%)\end{array}$ & $\begin{array}{l}\text { Difference } \\
\text { in } \\
\text { halfwidth } \\
(\mathrm{nm})\end{array}$ \\
\hline & & & \\
\hline (a) Proteins & -18 & -1.6 & -0.2 \\
Myosin & +64 & +5.2 & -1 \\
HMM & +14 & +9.2 & -1 \\
Tropomyosin & +40 & +19.2 & -0.5 \\
Aldolase & -1015 & -47 & +34 \\
19 kDa protein & -443 & -28.4 & +18 \\
DNAase 1 & $+11^{*}$ & $-1^{*}$ & $-1^{\star}$ \\
Profilin & +76 & -6 & +2 \\
& $+6^{\star}$ & $+7^{\star}$ & $+1^{*}$ \\
(b) Drugs & & & 0 \\
Cytochalasin B & -1 & -1 & +2 \\
Cytochalasin D & -54 & -13 & -1 \\
Phalloidin & +16 & +1.7 & +17 \\
(c) Control & & & \\
F- to G-actin & -772 & -34 & \\
& & & \\
\hline
\end{tabular}

and drugs were added in molar excess over actin promoters. After mixing, the fluorescence emission spectrum of the PRODAN-actin was recorded periodically until no further change was noted. The spectral characteristics obtained at steady state are compiled in Table 1. The increase in the integrated intensity observed upon addition of HMM, tropomyosin and aldolase to the modified actin proves (even if this increase is only small, as with HMM) that these proteins do interact with PRODAN-labelled F-actin. The positive difference in the emission energy corroborates this notion, although, in view of an estimated determination error of $\pm 20-30 \mathrm{~cm}^{-1}$, these differences are only significant for $\mathrm{HMM}$ and aldolase, and not for tropomyosin. The binding of HMM and of aldolase appears to change the environment of the PRODAN fluorophore, and the increases both in the emission energy and in the intensity suggest that the probe becomes even more buried within the protein complex than it is in the F-actin structure. For the case of HMM binding, evidence for a conformational change to actin has been obtained by fluorescence anisotropy measurements using 1,5AEDANS-labelled actin. It has been inferred from these data that the mobility of the probe decreases (Miki et al., 1982). The blue shift of the emission energy of PRODAN-F-actin upon HMM binding confirms this proposal. It remains to be established if HMM binding leads allosterically to a conformational change in the F-actin structure around the probe or if HMM shields the probe directly against the environment, which would be a conceivable alternative since an actin-myosin interface has been mapped close to Cys-374 (Lin, 1978). A similar effect might have been expected when myosin is bound. However, myosin could only be tested in the presence of $0.5 \mathrm{M} \mathrm{NaCl}$, because it precipitates under the low-salt conditions used for testing the other proteins. The presence of salt may make a difference. There are subtle differences in the F-actin structure depending on the ionic strength and the ratio of univalent to bivalent ions (Kasai et al., 1962), so that the association with myosin may not alter this structure in a manner comparable to the change caused by HMM under low-salt conditions.

The blue shift in the emission energy upon binding of aldolase might also signal an increased shielding. The binding site of aldolase on the actin polypeptide has been mapped in the vicinity of Met-299 by competition with region-specific antibodies (Méjean et al., 1989). According to the 3-dimensional model of actin (Kabsch et al., 1990) this region is in sub-domain 3, i.e. fairly distant from the C-terminus which is in sub-domain 1 . Therefore the binding of the enzyme affects the environment of PRODAN indirectly.

If the interaction between $\mathrm{F}$-actin and actin-binding proteins and drugs is accompanied by the liberation of monomeric actin, a decrease in the emitted fluorescence intensity and a red shift of the emission energy would be expected. DNAase I was chosen to prove this prediction, since depolymerization by DNAase I of unlabelled F-actin (Hitchcock, 1980; Mannherz et al., 1980) and of pyrene-actin (Pinder and Gratzer, 1982) is well documented. The PRODAN-F-actin conjugate appeared equally amenable to depolymerization by DNAase I as was unmodified actin. Figure 2 shows that the time course of the red shift of the emission energy, which is indicative of the liberation of monomeric actin, exactly paralleled the decrease in viscosity seen when DNAase I reacted with unlabelled F-actin. In this particular case it seems of no concern that these monomers are presumably associated with DNAase I in a binary complex. The fluorescence characteristics of monomeric PRODAN-G-actin were unaltered by complex formation with DNAase I (Table 1). That the enzyme formed a complex with the modified G-actin was proved by the fact that DNAase I effectively inhibited polymerization of PRODAN-Gactin (results not shown).

Profilin from spleen has been reported to form a tight complex with G-actin. It does inhibit the polymerization rate and the extent of filament formation, but it does not disassemble F-actin 


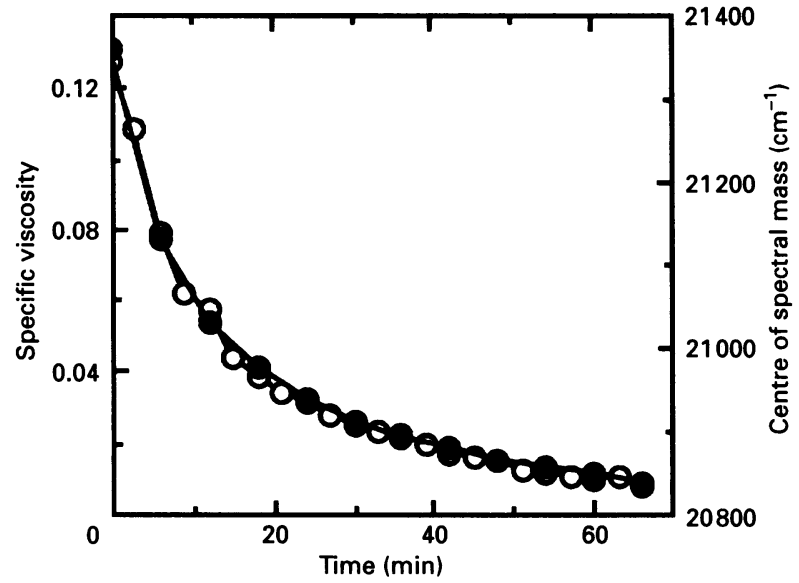

Figure 2 Comparison of the time course of depolymerization of unlabelled and PRODAN-labelled actin by DNAase I

O. Fluorescence of PRODAN-actin; - viscosity of unlabelled actin. The actin concentration was $2.34 \mu \mathrm{M}$ in both cases, and DNAase I was added in a 2-fold molar excess.

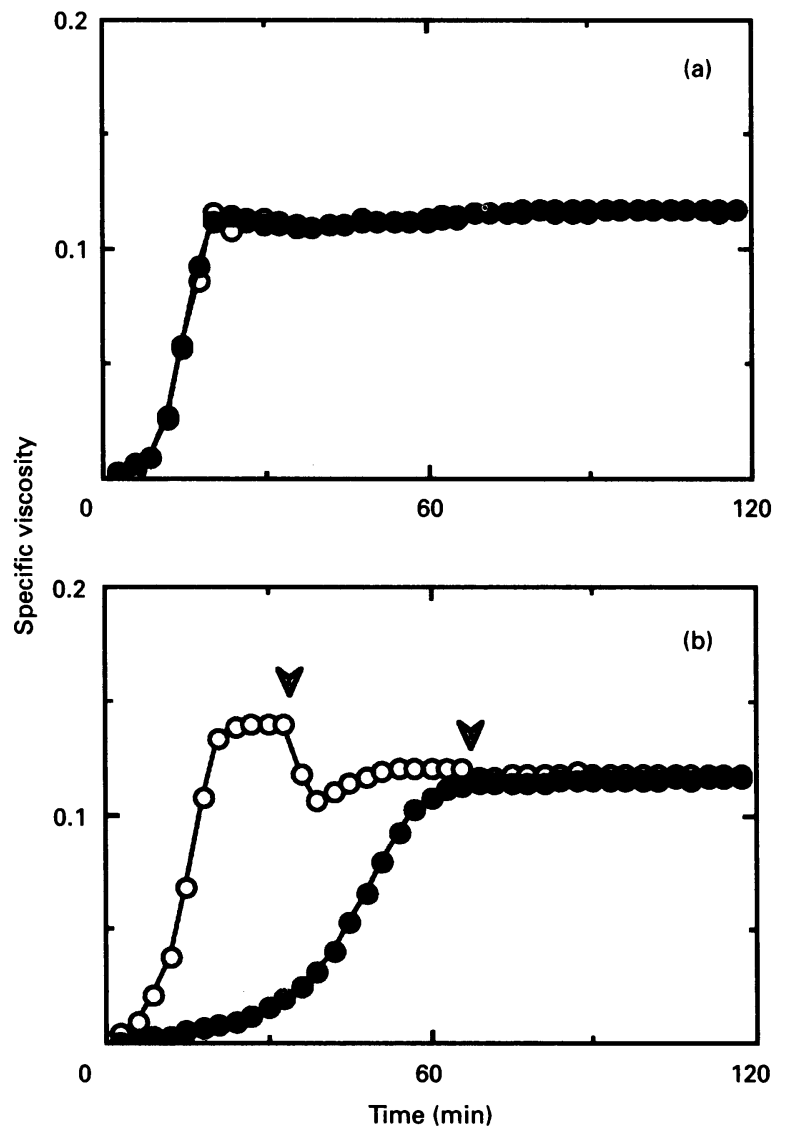

Figure 3 Action of profilin on PRODAN-labelled and unlabelled actin

(a) PRODAN-labelled actin: $2.34 \mu \mathrm{M}$ G-actin in G-buffer was induced to assemble by addition of $\mathrm{MgCl}_{2}$ to $2 \mathrm{mM}$ final concentration in the absence $(O)$ or in the presence $(O)$ of $14 \mu \mathrm{M}$ profilin. (b) Unlabelled actin. $O, 2.34 \mu \mathrm{M} \mathrm{G}$-actin was polymerized as in (a); at the times indicated by the arrowheads, profilin was added to a final concentration of $7 \mu \mathrm{M}$ and $14 \mu \mathrm{M}$ respectively. $14 \mu \mathrm{M}$ profilin was added to $\mathrm{G}$-actin before induction of assembly by $\mathrm{MgCl}_{2}$.

(Carlsson et al., 1977). The spleen profilin used in this study showed exactly the published characteristics (Malm et al., 1983; Nishida, 1985) when it was tested with unlabelled actin (Figure

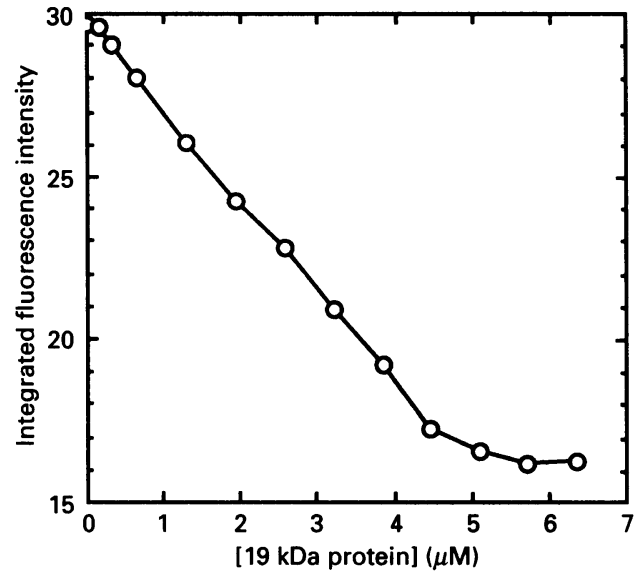

Figure 4 Titration of PROD.AN-F-actin with $19 \mathrm{kDa}$ protein

PRODAN-actin $(4.0 \mu \mathrm{M})$ was allowed to polymerize in G-buffer $+2 \mathrm{mM} \mathrm{MgCl}_{2}$ in a final volume of $400 \mu$ l. Aliquots of $1 \mu \mathrm{l}$ of appropriately diluted $19 \mathrm{kDa}$ protein were added, and the contents of the cuvette were mixed after each addition. The values shown are corrected for buffer fluorescence and for the dilution caused by the addition of the $19 \mathrm{kDa}$ protein solution (maximally $3 \%$ )

3b). However, in the viscometry assay it did not inhibit the polymerization rate of PRODAN-labelled G-actin (Figure 3a), nor did it decrease the steady-state viscosity when it was added to PRODAN-F-actin (results not shown). Spleen profilin is apparently sensitive to modification of Cys-374 by fluorescent probes. The steady-state fluorescence data (Table 1) suggest an interaction between both proteins, but the viscometry assay (Figure 3) shows clearly that the PRODAN group appears to impair the interaction of spleen profilin with the modified actin to such an extent as to suspend the inhibitory effect of profilin on polymerization. In this respect PRODAN-labelled actin is comparable with actins modified by either NEM or a pyrenyl group at Cys-374. These conjugates have been found to polymerize almost normally in the presence of spleen profilin (Malm, 1984), indicating that the modification of Cys-374 interferes with the interaction of spleen profilin with actin. It would be interesting to see if profilin from Acanthamoeba castellanii would interact with PRODAN-actin. This profilin binds to actin labelled at Cys-374 with pyrene or rhodamine, and in doing so enhances the fluorescence of the probe (Lee et al., 1988).

\section{The interaction of PRODAN-F-actin and $19 \mathrm{kDa}$ protein}

Addition of $19 \mathrm{kDa}$ protein to PRODAN-F-actin resulted in a rapid decrease in the integrated intensity and a decrease in the average emission energy. At an excess of $19 \mathrm{kDa}$ protein over actin at steady state both the integrated intensity and the average emission energy were lower than the corresponding values for PRODAN-G-actin, and the halfwidth of the resulting spectrum exceeded that of G-actin (Table 1). The extent of the fluorescence change at steady state appeared to be linearly dependent on the $19 \mathrm{kDa}$ protein concentration. It reached a plateau value at a molar ratio of $19 \mathrm{kDa}$ protein/actin protomers of 1.17 , which suggests a 1:1 stoichiometric interaction (Figure 4). These fluorescence data appear to indicate extensive disassembly of the filament structure. However, when viscometry was used to monitor such a titration, substantial residual viscosity remained even in the presence of excess $19 \mathrm{kDa}$ protein, regardless of whether PRODAN-labelled or unlabelled actin was used. The steady-state value of the viscosity was the same when $19 \mathrm{kDa}$ protein was added to $\mathrm{F}$-actin or to $\mathrm{G}$-actin prior to 


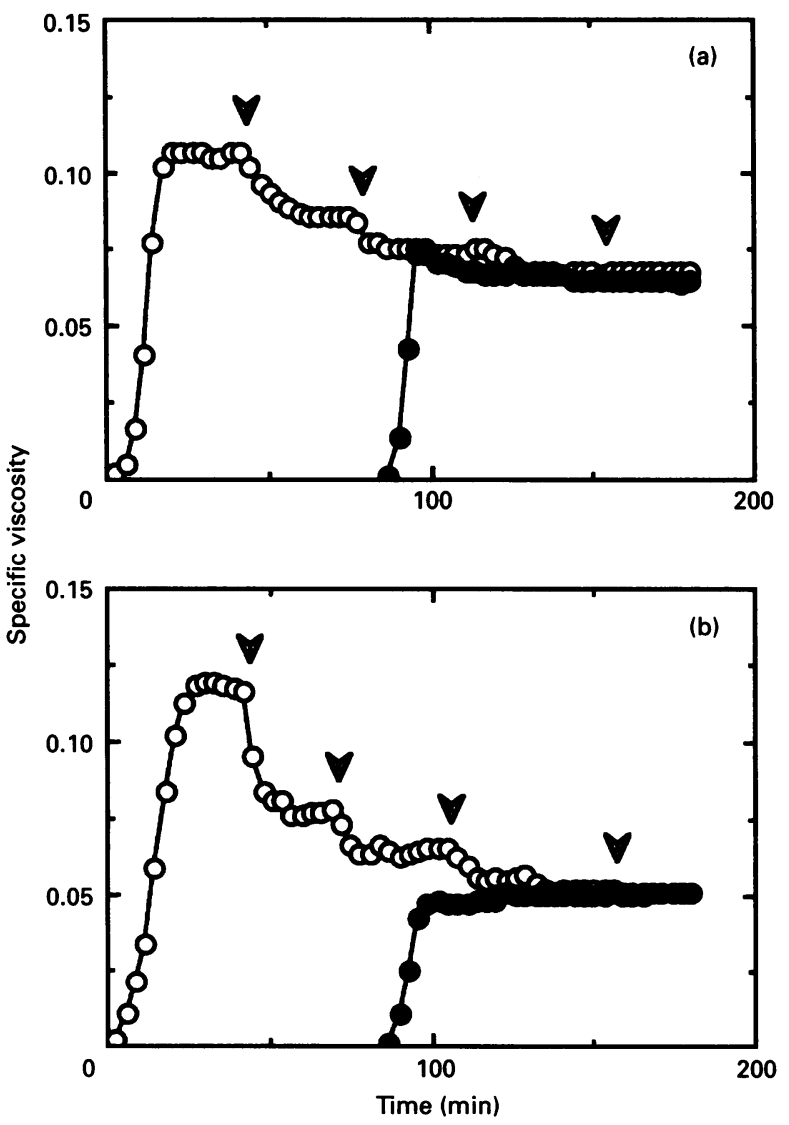

Figure 5 Interaction of PRODAN-labelled and unlabelled F- and G-actin with $19 \mathrm{kDa}$ protein followed by viscometry

A concentration of $2.34 \mu \mathrm{M}$ PRODAN-G-actin (a) or unlabelled G-actin (b) was assembled by the addition of $\mathrm{MgCl}_{2}$ to $2 \mathrm{mM}$ final concentration. At the times indicated by the arrowheads, $1 \mu \mathrm{l}$ aliquots of a concentrated $19 \mathrm{kDa}$ protein solution were added until no further change in the viscosity was observed $(O)$. The same saturating amount of $19 \mathrm{kDa}$ protein was mixed with $\mathrm{G}$-actin before induction of polymerization by $\mathrm{MgCl}_{2}(\mathbf{O})$. The start of the polymerization has been offset by 90 min to show the exact superposition of the final viscosity levels.
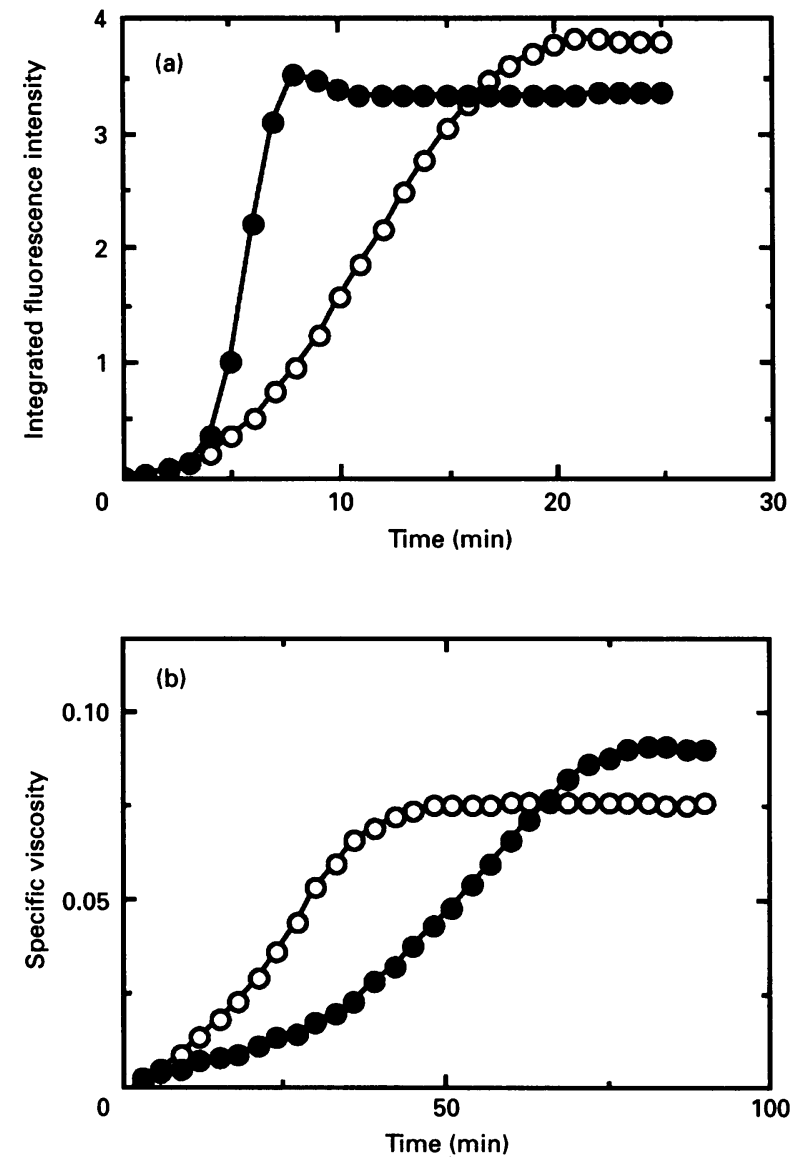

Figure 6 Acceleration of the polymerization of G-actin by 19-kDaprotein-actin complex

(a) PRODAN-G-actin (4 $\mu \mathrm{M}$ ) in G-buffer was induced to polymerize by addition of $\mathrm{MgCl}_{2}$ to $2 \mathrm{mM}$ final concentration. The fluorescence was excited at $410 \mathrm{~nm}$, and the emission recorded at $450 \mathrm{~nm}$. $\mathrm{O}$. Control without $19 \mathrm{kDa}$ protein; - as before, plus $0.25 \mu \mathrm{M} 19-\mathrm{kDa}$ protein-actin complex taken from a titration experiment as depicted in Figure 4. (b) Unlabelled G-actin $(1.53 \mu \mathrm{M})$ in G-buffer was induced to polymerize as above, and the changes in the viscometry were recorded periodically. Without $19 \mathrm{kDa}$ protein; $\mathrm{O}$, with $0.25 \mu \mathrm{M} 19-\mathrm{kDa}$ protein-actin complex. Different polymerization rates resulted from the different actin concentrations used in (a) and (b).

cations (Figure 6; see also Nishida et al., 1984). 19-kDaprotein-actin complexes can presumably serve effectively as nuclei for the initiation of the rapid growth of filaments, since the observed fluorescence change is four times faster in the presence of small amounts of 19-kDa-protein-actin complexes than in their absence. However, since this acceleration of polymerization by 19-kDa-protein-actin complex has also been observed with unmodified actin using viscometry to monitor the changes (Figure $6 b)$, it is not related to the attachment of the PRODAN moiety to the actin polypeptide.

\section{The interaction of PRODAN-G-actin and the $19 \mathrm{kDa}$ protein}

Titration of PRODAN-G-actin with the $19 \mathrm{kDa}$ protein at subcritical concentrations of G-actin was accompanied by a noticeable decrease in the fluorescence emission intensity (Figure 7). The centre of the spectral mass was not altered (results not shown). Since the actin concentration was six times lower than the critical concentration, and the measurements were taken in G-buffer, no polymerization was possible. The observed changes were apparently solely the result of the association of $19 \mathrm{kDa}$ when they are added at low concentrations to a G-actin solution before the polymerization reaction is initiated by bivalent and severing. A detailed mechanistic explanation, however, is so far not available.

The 19-kDa-protein-actin complexes which result from the action of $19 \mathrm{kDa}$ protein on F-actin, and which exhibit the residual viscosity, are excellent accelerators of the polymerization 


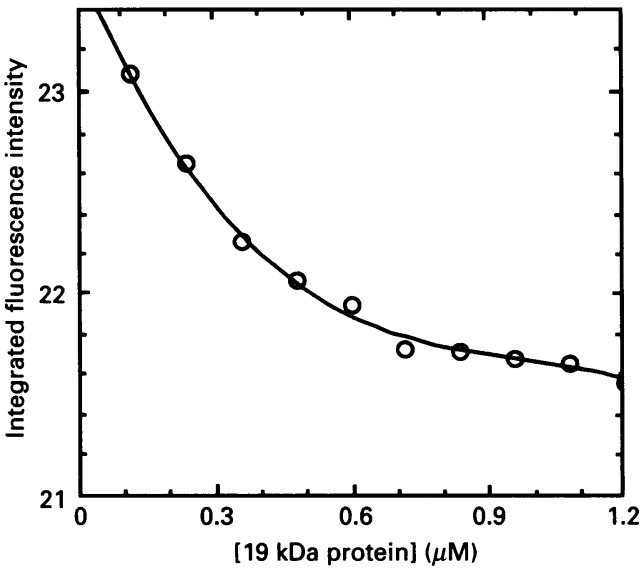

Figure 7 Titration of PRODAN-G-actin with $19 \mathrm{kDa}$ protein

PRODAN-G-actin (50 nM) in G-buffer was titrated with $19 \mathrm{kDa}$ protein as in Figure 4 in a final volume of $1.4 \mathrm{ml}$. The experimental data are represented by the points and the continuous line resulted from a computer fit based on a $K_{\mathrm{d}}$ of $0.25 \mu \mathrm{M}$.

protein with PRODAN-G-actin. The experimental data could be fitted using a dissociation constant, $K_{\mathrm{d}}$, equal to $0.25 \mu \mathrm{M}$ (solid line, Figure 7). This value is in good agreement with the value of $0.20 \mu \mathrm{M}$ reported for the binding of cofilin to actin under similar conditions (Nishida, 1985).

\section{The interaction of PRODAN-F-actin with cytochalasins D and B, and phalloidin}

The test of the effects of cytochalasin D and cytochalasin B on PRODAN-F-actin (Figure 8) revealed an interesting new aspect of the interaction of cytochalasin D with F-actin. Cytochalasin D caused an unexpected slow decrease in the integrated fluorescence intensity when it was added to PRODAN-F-actin (Figure 8). This is quite in contrast to the at least 10 times faster drop of the viscosity that is observed when unlabelled F-actin is treated with cytochalasin D (Figure 8b; see also Howard and Lin, 1979; Brenner and Korn, 1979). The ability of cytochalasin D to raise the critical actin concentration by capping the net polymerizing end of filaments has been well documented (Rickard and Sheterline, 1986; Godette and Frieden, 1986). The results shown in Figure 8(a) indicate that this process appears to be slow when it proceeds without interference by the fluorescence measurement, but may be greatly accelerated when multiple filament fragmentation occurs through the mechanical shear exerted by viscometry measurements. In addition, cytochalasin $\mathrm{D}$ may enhance the susceptibility of actin filaments to breakage by shear force, as does cytochalasin B (Bonder and Mooseker, 1986). Cytochalasin B has no capping activity and does not raise the critical actin concentration (Fussmann and Dancker, 1986). Consequently no decrease in the fluorescence is to be expected, and none has been observed (Figure 8a). The drop in viscosity (Figure 8b; see also Spudich and Lin, 1972; Yahara et al., 1982) may reflect the decrease in the average filament length by a limited cleaving activity of cytochalasin B that has been reported by Urbanik and Ware (1989).

The fluorescence emission of the PRODAN-F-actin conjugate did not show a significant response upon the addition of phalloidin, a toxin from the poisonous mushroom Amanita phalloides, which interacts with F-actin and stabilizes the
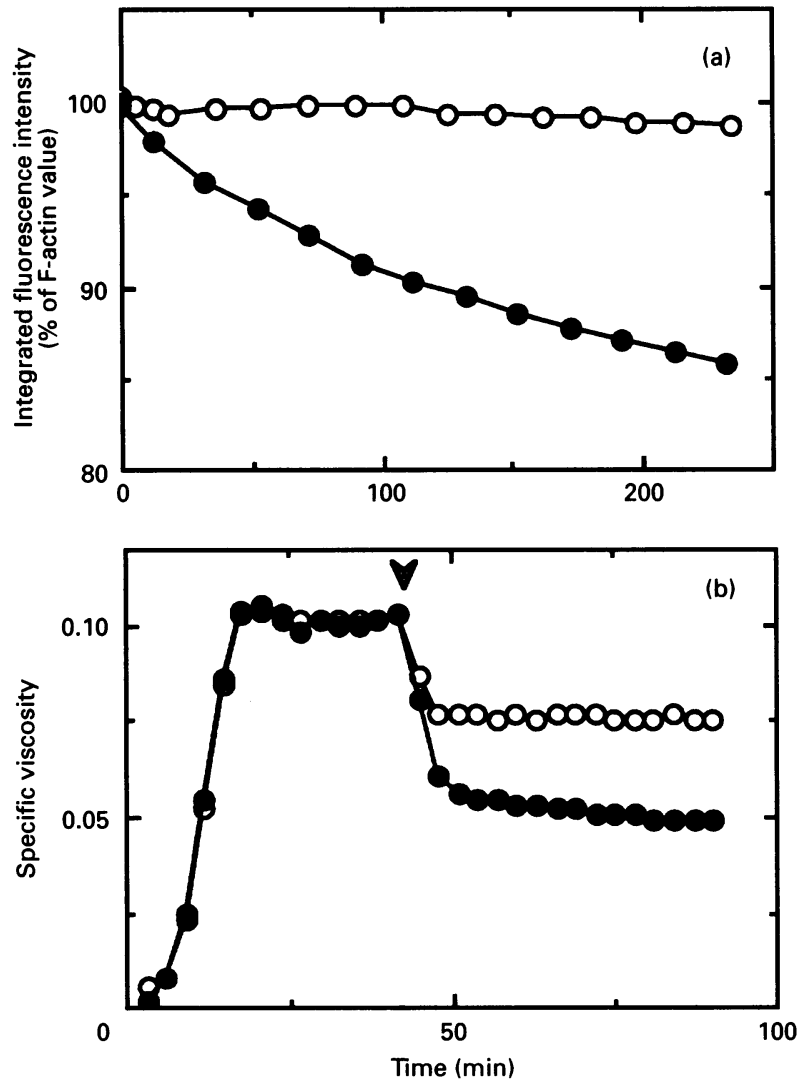

Figure 8 Effect of cytochalasins B and D on PRODAN-F-actin

(a) PRODAN-F-actin $(2.34 \mu \mathrm{M})$ was incubated with $60 \mu \mathrm{M}$ cytochalasin B (O) or $60 \mu \mathrm{M}$ cytochalasin $\mathrm{D}(\boldsymbol{O})$ and fluorescence emission spectra were taken at the intervals indicated by the points. (b) PRODAN-G-actin $(2.34 \mu \mathrm{M})$ was induced to assemble by addition of $\mathrm{MgCl}_{2}$ to $2 \mathrm{mM}$ final concentration. At the time indicated by the arrowhead a concentrated solution of cytochalasin $\mathrm{B}(\mathrm{O})$ or cytochalasin $\mathrm{D}(\boldsymbol{)})$ in dimethyl sulphoxide was added to give a $60 \mu \mathrm{M}$ final concentration. A correction was made for the viscosity change due to the dimethyl sulphoxide.

filamentous structure (Dancker et al., 1975) (Table 1). It seems unlikely, although it has not been excluded, that the modification of Cys-374 by PRODAN interferes with the binding of phallodin because neither NEM (Vandekerckhove et al., 1985; Miki, 1989) nor fluorescein (Miki and dos Remedios, 1988) attached to this amino acid residue impairs the interaction between phalloidin and these conjugates. The phalloidin-binding site has been located near amino acid residues 117-119. Although these residues are within the same sub-domain 1 as the C-terminus (Kabsch et al., 1990), the binding of the drug has apparently no influence on the environment of the fluorophore at Cys-374.

I thank Dr. G. Marriott for much helpful advice during the measurements, and for critical comments on the manuscript.

\section{REFERENCES}

Bamburg, J. R., Harris, H. E. and Weeds, A G. (1980) FEBS Lett. 121, 178-182 Berl, S., Chou, M. and Mytilineou, C. (1983) J. Neurochem. 40, 1397-1405

Bonder, E. M. and Mooseker, M. S. (1986) J. Cell Biol. 102, 282-288

Brenner, S. L. and Korn, E. D. (1979) J. Biol. Chem. 254, 9982-9985

Carlsson, L., Nyström, L.-E., Sundkvist, I., Markey, F. and Lindberg, U. (1977) J. Mol. Biol. 115, 465-483

Cooper, J. A., Walker, S. B. and Pollard, T. D. (1983) J. Muscle Res. Cell. Motil. 4. 253-262

Cummings, P. and Perry, S. V. (1973) Biochem. J. 133, 765-777 
Dancker, P., Löw, I., Hasselbach, W. and Wieland, T. (1975) Biochim. Biophys. Acta. 400 , $407-414$

Detmers, P., Weber, A., Elzinga, M. and Stephens, R. E. (1981) J. Biol. Chem. 256, 99-105

Doi, Y. and Frieden, C. (1984) J. Biol. Chem. 259, 11868-11875

Elzinga, M. and Collins, J. H. (1975) J. Biol. Chem. 250, 5897-5905

Fussmann, B. and Dancker, P. (1986) Z. Naturforsch. 41c, 781-786

Giuliano, K. A., Khatib, F. A., Hayden, S. M., Daoud, E. W. R., Adams, M. E., Amorese,

D. A., Bernstein, B. W. and Bamburg, J. R. (1988) Biochemistry 27, 8931-8938

Godette, D. W. and Frieden, C. (1986) J. Biol. Chem. 261, 15974-15980

Hamming, R. W. (1973) Numerical Methods for Scientists and Engineers, 2nd edn., pp. 473-494, McGraw-Hill, Tokyo

Hitchcock, S. E. (1980) J. Biol. Chem. 255, 5668-5673

Howard, T. H. and Lin, S. (1979) J. Supramol. Struct. 11, 283-293

Kabsch, W., Mannherz, H.-G., Suck, D., Pai, E. F. and Holmes, K. C. (1990) Nature (London) 347, 37-44

Kasai, M., Asakura, S. and Oosawa, F. (1962) Biochim. Biophys. Acta 57, 13-21

Kouyama, T. and Mihashi, K. (1981) Eur. J. Biochem. 114, 33-38

Laemmli, U. K. (1970) Nature (London) 227, 680-685

Lakowicz, J. R. (1983) Principles of Fluorescence Spectroscopy, p. 226, Plenum Press, New York

Lee, S., Li, M. and Pollard, T. D. (1988) Anal. Biochem. 168, 148-155

Lin, T. (1978) Arch. Biochem. Biophys. 185, 285-299

Lowey, S. and Cohen, C. (1962) J. Mol. Biol. 4, 293-308

Lusty, C. J. and Fasold, H. (1969) Biochemistry 8, 2933-2939

MacLean-Fletcher, S. and Pollard, T. D. (1980) Biochem. Biophys. Res. Commun., 96, 18-27

Maekawa, S., Nishida, E., Ohta, Y. and Sakai, H. (1984) J. Biochem. (Tokyo) 95, 377-385 Malm, B. (1984) FEBS Lett. 173, 399-402

Received 29 June 1992/17 September 1992; accepted 10 October 1992
Malm, B., Larsson, H. and Lindberg, U. (1983) J. Muscle Res. Cell Motil. 4, 569-588 Mannherz, H. G., Goody, R. S., Konrad, M. and Nowak, E. (1980) Eur. J. Biochem. 104, $367-379$

Marriott, G., Zechel, K. and Jovin, T. M. (1988) Biochemistry 27, 6214-6220

Matsuzaki, F., Matsumoto, S., Yahara, I., Yonezawa, N., Nishida, E. and Sakai, H. (1988) J. Biol. Chem. 283, 11564-11568

Méjean, C., Pons, F., Benyamin, Y. and Roustan, C. (1989) Biochem. J. 264, 671-677

Miki, M. (1989) J. Biochem. (Tokyo) 106, 651-655

Miki, M. and dos Remedios, C. G. (1988) J. Biochem. (Tokyo) 104, 232-235

Miki, M., Wahl, P. and Auchet, J.-C. (1982) Biochemistry 21, 3661-3665

Nishida, E. (1985) Biochemistry 24, 1160-1164

Nishida, E., Maekawa, S. and Sakai, H. (1984) Biochemistry 23, 5307-5313

Pinder, J. C. and Gratzer, W. B. (1982) Biochemistry 21, 4886-4890

Pollard, T. D. (1982) Methods Cell Biol. 24, 333-371

Porter, M. and Weber, A. (1979) FEBS Lett. 105, 259-262

Prendergast, F. G., Meyer, M., Carlson, G. L. lida, S. and Potter, J. D. (1983) J. Biol. Chem. 258, 7541-7544

Rickard, J. E. and Sheterline, P. (1986) J. Mol. Biol. 191, 273-280

Spudich, J. A. and Lin, S. (1972) Proc. Natl. Acad. Sci. U.S.A. 69, 442-446

Spudich, J. A. and Watt, S. (1971) J. Biol. Chem. 246, 4866-4871

Tao, T. and Cho, J. (1979) Biochemistry 18, 2759-2765

Tawada, K., Wahl, Ph. and Auchet, J. C. (1978) Eur. J. Biochem. 88, 411-419

Urbanik, E. and Ware, B. R. (1989) Arch. Biochem. Biophys. 269, 181-187

Vandekerckhove, J., Deboben, A., Nassal, M. and Wieland, T. (1985) EMBO J. 4, 2815-2818

Yahara, I., Harada, F., Sekita, S., Yoshihira, K. and Natori, S. (1982) J. Cell. Biol. 92, 69-78

Zechel, K. (1981) Eur. J. Biochem. 119, 209-213

Zechel, K. (1983) Hoppe-Seyler's Z. Physiol. Chem. 364, 1233-1234

Zimmerle, C. T. and Frieden, C. (1986) Biochemistry 25, 6432-6438 